\title{
The Effective Application Research of Emotional Teaching in the Erhu Teaching
}

\author{
Saisai Ma \\ Xi'an Conservatory of Music, Xi'an, Shaanxi Province, China \\ 1857881@qq.com
}

Keywords: Erhu teaching, Emotional teaching, Effective application, Application research

\begin{abstract}
Erhu has a history of more than one thousand years in China, over the past century, it's developing rapidly, and attracting more and more attention. But as a result of the erhu teaching history is shorter, using techniques are not appropriate, also will not be able to transfer the students' interest in learning. Have to admit, erhu also produced many problems in the actual teaching. From the perspective of emotional teaching, this paper discusses the problems existing in the current erhu teaching, and puts forward some solutions.
\end{abstract}

\section{Introduction}

Erhu is also known as "premiere", is a kind of folk Musical Instruments in the north of China, first appeared in the Tang dynasty, Tang dynasty poet C. C. Ceng in "white snow song to force the judge to Beijing" wrote "J. Zhong buy wine for the guest, the urheen pipa and QiangDi", the development of erhu has a long history [1]. As a kind of attractive bowed stringed instrument, the erhu for dark, tragic content, at the same time can also describe is spectacular, spectacular artistic conception, in the first thousand years of development, produced many excellent representative repertoire, including artistic conception far-reaching on two springs, SOB "river water", the magnificent Great Wall scribbling, Pentium passionate "horse race" and the thoughts of "feast Sanmenxia lake" and so on.

In erhu playing skills is an important part of the emotional also plays an indispensable role in it, emotion in the play, emotion in the works of artistic conception, can play out or SOB, or magnificent repertoire, become the erhu masters. At present, China's colleges and universities of erhu teaching universal attention to the cultivation of skills for erhu, ignore the emotional in the important role in the process of students' learning erhu [1]. How emotion in erhu teaching, give students a rich emotional experience, so as to improve the teaching quality of the erhu, become an important problem facing the erhu teacher.

\section{The importance of emotion in erhu art}

Psychological factors of self-control. In Hegel's "aesthetics" repeatedly stressed that the content of the music is a form of emotional, thought only emotion is music to some areas". In this field, the music is extended to express all the different special feelings [1]. This shows, music and people's emotional life is really touch, music left the emotional expression, it is out of the music and people's feelings, abandoned music to some special functions.

The creation of the erhu is a subjective process. Players must bring the rational factors of deliberate self control and emotional factors of fiery passion together, as well as to faithfully reproduce the original music must have a strong sense of participation and highly creative enthusiasm, creativity and to embody the performers enter their feelings, thoughts, wisdom and ability to make every music performances as a creation, give life to note.

Mastery of timbre. In the feeling of tone and power of action, in order to obtain good touch feeling, as the direct effects on the strings fingers have a kind of "refers to the sense of", make the conscious feelings of music "potential" into "skills" of movement performance. This transformation 
process in the sound, emotion, feeling and skills constantly adjust and perfect combination, make the action consciousness psychology and psychological reached the height of the harmonious music thought, and embodied in the perfect play feeling [1]. This feeling of playing in the combination of the overall consciousness of action, not only for the action of feeling "integration", and in the sound, feeling repeatedly updated playing, performing group to form a new skill. This is love, gas, and power, rhyme music performance factors such as form, color, and technology comprehensive sensory system with the technique of open structure to replace the stylized model of technical skills.

\section{The role of emotional teaching in the teaching of erhu}

Emotional teaching refers to the teachers' teaching by certain means; meet the emotional needs of students, so as to improve the teaching methods of the teaching effect. Emotion is the necessary condition of human survival in the erhu teaching reasonable use and adjusting students' emotion, can active classroom atmosphere, calmed the nerves of students in the class, effectively arouse the students' non-intelligence factors, so as to achieve the aim of improving the efficiency of classroom [2]. At present, China's colleges and universities of erhu focuses on teaching on give students some basic theoretical knowledge and skill, ignore the importance of emotional teaching in students' learning erhu process, lead to classroom teaching boring, low quality of classroom teaching. Therefore, strengthen the emotional teaching in China's colleges and universities of erhu teaching, the application of to improve the students' interest in learning, deepen the students on the erhu and the music works of emotional experience, so as to improve the teaching quality of the erhu, has the very vital significance.

Inner feelings are need players to understand, and then the external action requires the performance of the players. Outer action is the expression of the inner feelings; the inner emotions are foundations of the external actions. Both supplement each other, inseparable. External actions include facial expressions and body movements, namely expression language and body language. Only use good expression language and body language, play is the art and infectious, rather than for technical and mechanical inflexible play, because it has injected alone is the heart of the players and emotional expression [2]. In the xi sent agricultural, for example, heartfelt joy freed in expression language and body language, also let the audience feel interaction. Of course, need players hold good scale in action here? Avoid by all means is mystifying, chichi soft affectation. Will play the color strength is blended in among them, brought the release of emotions. Emotional interaction with the audience feedback and accept, it is through the different expression language and body language, form a complete image of the music. In the play, keep the inner emotions and external action of unity, the rational use of emotion; let it serve for the performing arts in real sense.

\section{The effective application of emotional teaching in the teaching of erhu}

Teachers play in demonstration and interpretation of emotional engagement. Modern scientific research by affection isYouJiao theory, teaching cognitive, heavier emotions. This is scientific and effective teaching strategy. The former Soviet Union educator Su Huom linsky said: "I am convinced that one thousand times without a poetic, emotional and aesthetic of the spring, is impossible to have the students comprehensive intellectual development". Establish good relationship between teachers and students, the new intelligence between teachers and students to play is a catalyst [3].

To exert the positive role of emotions in erhu teaching, teachers should set an example, first in erhu increase the investment of emotion in the teaching process, and play a good exemplary role for the students. Teachers in the teaching process is full of emotion demonstration of play and the music, can effectively infection and stimulate the development of students, make students unknowingly into the works of artistic conception, more profound understanding of the theme of the works. The emotional input of erhu teaching teachers are mainly concentrated in two aspects: emotional input and contents of demonstration performance interpretation of emotional engagement. 
First is a teacher when teaching music works for emotional engagement. Each author's emotion is a erhu repertoire involve in it, so the teacher should also try to show when the interpretation of such a kind of emotion, through the interpretation of affectionately, inspire students' emotion, so as to deepen students understanding emotion of the works, and motivate them to work performance desire [3]. For example, in the teaching of "river water" this work, the teacher can let students know about the historical background of the feudal society at that time, the ruling class regardless of the suffering people, blindly, causing people displaced, husband and wife separation, gloom, allow students to truly feel at that time, people in the heart of that kind of sad mood, students on the basis of the understanding of works and playing the effect will be better.

Following by the demonstration process of emotional engagement,teachers play a demonstration in class, students can to teacher's expression, action and meticulous observation, practice erhu in the students themselves, they will consciously or unconsciously imitate the teacher's behavior, therefore, erhu teachers should increase the emotional input of demonstration performance, used to strengthen the emotional teaching in the teaching of erhu [3]. Did the two springs month, for example, many people have heard of, but the students hear on the radio or computer methods such as impressed by this song, is much less than the teachers in the classroom for students hands-on play left deep impression. So, the teacher's demonstration is the student to learn erhu first emotion source, increase the emotional input of demonstration performance, can effectively promote students to learn erhu when emotional experience.

Multiple teaching methods to improve students' music. If want to let the student active learning, you must be able to let him take an interest in learning, in the music teaching of the past, students to sing a song, to play a musical instrument performance is not strong, in addition to the limitation of some objective conditions, is more of a lack of understanding and understanding of these instruments [4]. In music teaching in the classroom in instrumental music teaching for basic, in the process of fun to play, let the students experience brought by the erhu classroom atmosphere, stimulate students to the feeling of the beautiful voice and interest in music learning.

Physiological conditions is restricted, as some students sing sing single teaching mode cannot have satisfied their needs, increase the erhu teaching can play a positive guidance, foster strengths and circumvent weaknesses, erhu teaching has a distinctive artistic quality, affective and skill. These features are induce the students' interest in erhu, through multimedia means in their spare time to appreciate various kinds of erhu music, can make students more deeply understand the artistic charm of erhu music, will improve students' interest in learning erhu, interest is the power of learning, have the interest to ensure the smooth progress of learning [4].

First, ask questions appropriately, arouse students' interest in learning. Erhu practice, especially the erhu etudes, pulls up a boring. How to make students interested in?Psychology shows that: to make a healthy, a man of curiosity for fresh knowledge produce genuine interest, it should not be difficult, because of the unknown is the most everyone wins, the most tempting process. Albert Einstein said: "ask a question, is often more important than to solve a problem" [5]. Learning with thought, ses in doubt, doubt is inspired to explore, to discover the truth.

Any invention starts from the question. Mr Tao xingzhi said: "never, starting point is invented in asking. The wise man asked, so ask stupid fools. Human wins the tico, only ask in everything. "In the teaching, teachers should not only guide students to boldly ask questions, and questions should leave room for students, lets the student in the independent inquiry to find out. At the same time, teachers should also cleverly put forward problems, cause the students' cognitive conflict, and stir up their interest. It should be noted that: the teacher questions easy to appropriate. Viggo, said: "if the problem created within the scope of knowledge, only simple exploration of the development of the brain, do not interest the students; if the question is too high, the cerebral cortex fuzzy one, will not only put the question in a particularly exciting recent development zone, can cause the greatest excitement. ", the zone of proximal development refers to the students with their own knowledge and ability, jump to reach areas. When the student has learned knowledge skills and new efforts to solve the problem, can produce a pleasant emotional experience, will further strengthen the lasting interest in learning. 
Second, make use of the computer aided teaching stimulate students interest in learning. Assisted by computer as the carrier of the modern teaching means to erhu teaching, to teaching process, the vivid figure of auxiliary teaching, stimulate the visual nerve of students, make students always maintained a high state of learning, so as to improve teaching efficiency. For example, plays the "horse race", the author use computer play courseware a few images of horse in the race, the horse running out "horse race" solo [5]. Ups and downs of rhythm and beautiful melody are deeply impressed by the students. Students involuntarily hum up this first Ai son, and then played in a graceful posture.

Third, vivid language stimulates students' interest in learning with accurate and vivid. Witty, humorous language teachers can attract the attention of students; arouse their learning enthusiasm, so that students in a relaxed, harmonious, and active and pleasant atmosphere, better practice, master the skills of erhu, skills [5]. Colorful language can stimulate students' interest in learning; it is because the interest is associated with certain emotions, and emotional mainly through language to express. Teachers in the demonstration of erhu techniques at the same time, such as the language art combined with superb, is good at using vivid, vivid language to tell the connotation of every section of erhu solo and rafa skills, can better stimulate students learning desire to practice, play the erhu.

With emotional understanding of music. Music is used to express emotion, a person thought that in the life, will unleash the creative inspiration of music [6]. Aesthetes Schopenhauer said: "music is not the same as other art, concept of other art just copy, concept is only the objectification of will, music itself is will copy, that's why music can effectively penetrate into the heart. "Music is a reflection of the creator's thoughts and feelings.

Generally each erhu learners, to get the first is the rational cognition, and music in addition to the understanding of music, and rich life experience and music accomplishment. Works include the strength, speed, sound color and formal structure. Background and life form and melody from an era of music style characteristics, experience of the author tries to express into music emotion. First, analyzing the speed of work, from single spectrum surface, music rhythm beats, decided the music expression markings overall speed, which can reflect the emotional content of music comprehensive;Second, start from the content analysis of works by reaction, deep understand the expressiveness of works, a deep understanding of the era background and creation of works creation style, is the important way, works of intension of better play [6]. Different players will produce different artistic image with a piece of music. On the basis of the original author to respect the author's intentions, to own understanding, is the creation of self personality.

Author tries to work in the heart of emotion, but also try to make other people understand their own emotions can through their own work, so a good writing can make the player and the listener to spy out to the author at the time of inner feelings. In erhu emotional teaching, the teacher first should guide and encourage students to use emotion to understand music, understand the erhu, and understand the full author bitterness and outstanding erhu works. When teachers in the teaching works of historical background can be introduced to students, and full of emotion to play for the student to carry on the demonstration, and then let the students to judge the theme of the works, style, etc, and to express their own feelings, and finally, teacher for students to understand some of the pitfalls of explanation, and summarized the content of the classroom [6]. Through this kind of sex of teaching, students can have a more profound understanding of emotions to work and sure, they are better at will in the play emotion is blended in among them, raise the level of play. In erhu emotional teaching, teachers should also pay attention to grasp student's psychology, to encourage more students, and to eliminate them in the process of learning erhu fidgety, dodging and other negative emotions, cultivate their self-esteem and confidence, will the teacher to student's care as a kind of emotion into the whole teaching process, to develop good relationship between teachers and students. In erhu teaching, teachers should try to communicate with students' debate against each other on an equal and eliminate barriers between teachers and students, the emotional teaching process, students in the learning environment of equality, freedom is easier to start thinking for learning and playing erhu. 
In addition, in conditions allow, teachers can organize the student to a feel for erhu famous erhu concert playing style and emotional factors in its expression in the process of playing, enrich the erhu teaching classroom life already so, increase the students' knowledge, also gave the students to learn erhu passion and motivation, to make them in the daily learning can more diligence, effort.

\section{Conclusion}

Erhu teaching and technique requirement is strict, the actual erhu teaching high school students is easy to appear some negative emotions, affect the improvement of the erhu. School should pay attention to the emotional teaching in the teaching of erhu advantages, enhance the students' feeling and understanding, actively guide students to better learn erhu, get the fun of learning, so that the teaching of erhu emotion better.

\section{References}

[1] W. Sh. Yuan, Into the new curriculum and curriculum implementer dialogue, Beijing normal university press, 2002, vol. 4, pp. 23-26.

[2] D. M. Chen, Emotional teaching in the teaching of erhu, journal of vocational and technical college, Harbin, 2013, vol. 3, pp. 43-48.

[3] D. F. Wang, Analysis of the application of emotional teaching in erhu teaching,China music education, 2013, vol. 5, pp. 54-58.

[4] Y. Y. Huang, Erhu performing arts study, People's music publishing house, 2011, vol. 8, pp. 11-14.

[5] R. M. Xue, Teaching theory of erhu, China international cultural publishing house, 2013, vol. 8, pp. 21-25.

[6] S. M. Yang, Erhu playing and teaching, Nanjing normal university press, 2012, vol. 3, pp. 54-57. 